\title{
Endometrioid Adenofibroma: A Case of This Uncommon Benign Tumor of the Ovary Not Associated to Borderline or Endometrioid Carcinoma
}

\author{
Santiago Ortiz* and Francisco Tortosa \\ Department of Pathology, Centro Hospitalar Lisboa Norte, EPE - Hospital de Santa Maria, Lisbon, Portugal
}

*Corresponding author: Santiago Ortiz, Department of Pathology, Centro Hospitalar Lisboa Norte - Hospital de Santa Maria, Avenida Professor Egas Moniz, 1649-035, Lisbon, Portugal, Tel: +351-217-805-166, E-mail: santi.orfer@gmail.com

\section{Keywords \\ Endometrioid adenofibroma, Ovary, Tumor}

Endometrioid adenofibroma is a benign epithelial and stromal tumor with an endometrioid epithelial component. Less than $20 \%$ of the surface epithelial tumors of the ovary have endometrioid differentiation [1]. The majority of endometrioid ovarian neoplasms are carcinomas and the benign form is rarely find. Endometrioid adenofibromas are extremely rare, comprise $1 \%$ of ovarian epithelial neoplasms. Usually, they are unilateral lesions (83\%) and clinical symptoms are non-specific [2]. Ovarian endometriosis (including endometriomas and endometriotic cysts) is by far more common than benign endometrioid neoplasms. Probably it represents endometriomas in which the endometrial stroma is indistinct.

Here we present an 81-year-old woman that was admitted because for uterine prolapse (grade IV), without incontinence symptoms. There is no history of any diseases, only hypertension. Routine ultrasounds revealed a well-defined tumor of the right ovary, with a diameter of about $4 \mathrm{~cm}$. Total hysterectomy with right oophorectomy was performed. The surgical specimen consisted of a hysterectomy weighing $74.2 \mathrm{~g}$ and $11 \times 5.5 \times 2.2$ $\mathrm{cm}$, and an oophorectomy with $4.3 \times 3.5 \times 3 \mathrm{~cm}$. The external surface of the ovary was smooth, displaying a firm consistency. The cut surface is compactly fibrous; it exhibited cystic areas creating a honeycomb appear-

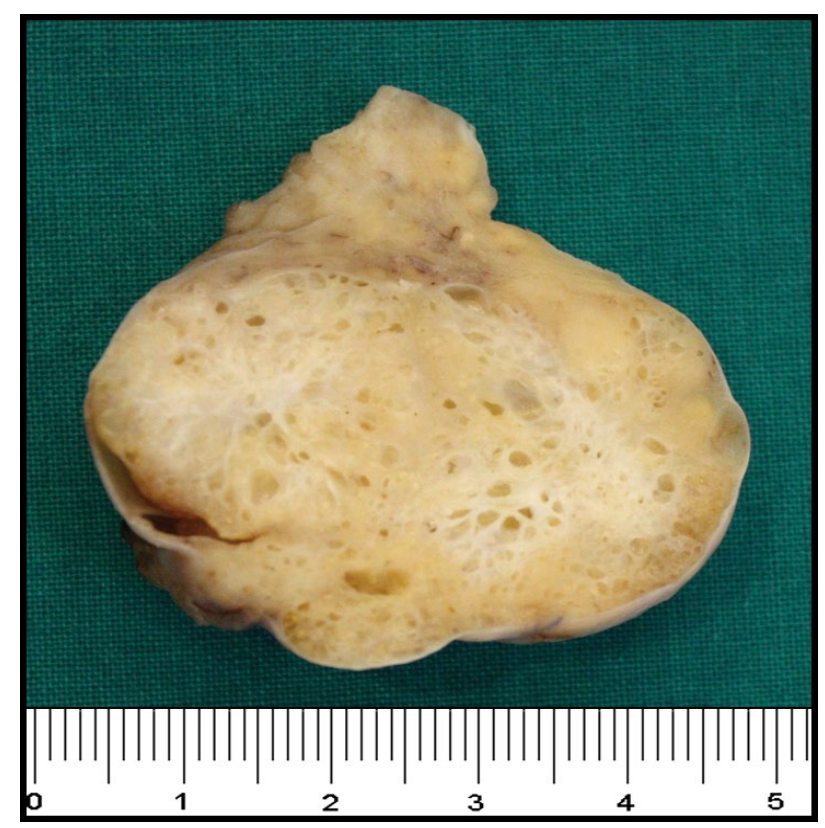

Figure 1: Endometrioid adenofibroma. Cut section showing variable sized of cystic spaces.

ance (Figure 1). The cysts were filled with a clear-yellowish fluid. Microscopically, the sections revealed a tumor composed of epithelial elements arranged in branching tubular glands and cysts, with variable size and shape. The epithelium lining the glands is cuboidal to columnar (often pseudostratified) with eosinophilic cytoplasm and oval, small and uniform nuclei containing coarse chromatin and small nucleoli. The glands are embedded in a fibromatous stroma. The fibromatous

Citation: Ortiz S, Tortosa F (2017) Endometrioid Adenofibroma: A Case of This Uncommon Benign Tumor of the Ovary Not Associated to Borderline or Endometrioid Carcinoma. Int J Pathol Clin Res 3:057. doi.org/10.23937/2469-5807/1510057

Received: October 29, 2016: Accepted: June 14, 2017: Published: June 16, 2017

Copyright: (C) 2017 Ortiz S, et al. This is an open-access article distributed under the terms of the Creative Commons Attribution License, which permits unrestricted use, distribution, and reproduction in any medium, provided the original author and source are credited. 


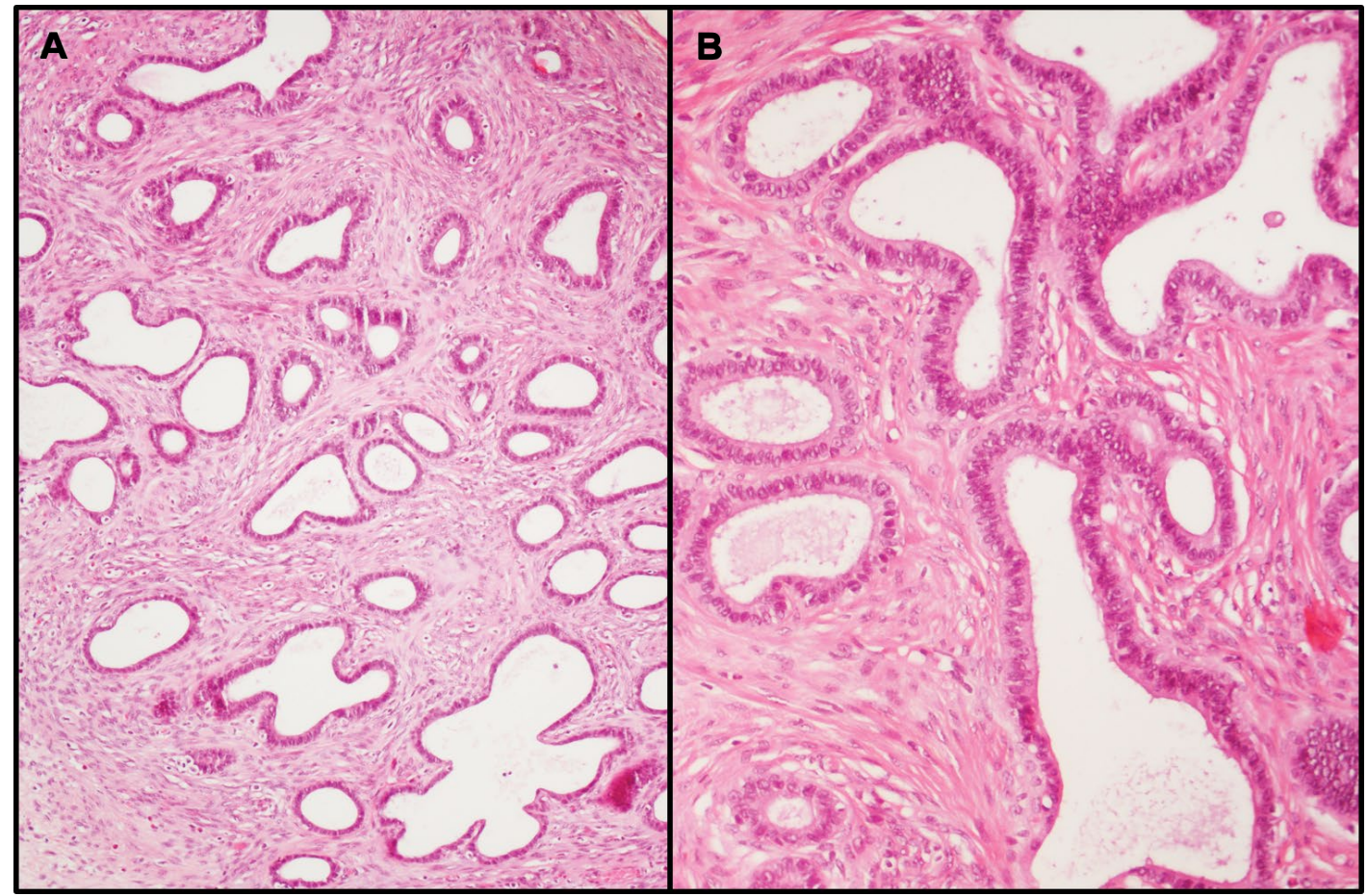

Figure 2: Histopathologic examination showed numerous irregularly shaped glands distributed throughout a fibromatous variably cellular stroma. There were no solid epithelial areas or endometrial stroma $(A-H \& E \times 100)$. The epithelial component was bland columnar cell nuclei $(B-H \& E \times 200)$.

component consists of small spindle cells, arranged in fascicles. Nuclear atypia is not present in the epithelium and stromal components. Mitoses is not observed (Figure 2). We made the diagnosis of endometrioid adenofibroma. At present the patient is alive and she has no evidence of others tumors or metastasis.

Endometrioid adenofibromas occur in the second to seventh decade of life, but most commonly in perimenopausal and postmenopausal women. The median age is 57 years [3]. Often, adenofibroma is serous type, but other epithelium can be see (mucinous, endometrioid and clear cells). Endometrioid adenofibromas may be difficult to differentiate from adenofibromas of other cell types, particularly Brenner tumors. Such distinction could be done based on histologic examination of the lining epithelial cells. The distinction of endometrioid adenofibroma from serous adenofibroma may be not easy, as both may have ciliated epithelium. Tubular glands and lack of the multiple cysts and fibrous papillae of serous adenofibroma favor endometrioid differentiation [2].

Adenofibromas typically occur in association with borderline tumors. The distinction between benign and borderline endometrioid tumors is based on the degree of architectural and cytologic atypia of the epithelial component. Closely packed cribriform glands and presence of any degree of cytologic atypia favor a diagnosis of borderline tumor [3]. Therefore, it is important that large tumors to be well sampled so that any borderline areas are not missed. A good gross examination will reveal any suspicious areas for sampling [4].
These tumors have benign clinical course, (no reports of recurrence) and successfully treated by oophorectomy [4]. Here we report a very infrequent case of endometrioid adenofibroma not associated to borderline tumor or endometrioid carcinoma, a very unusual presentation, on the contrary to the most case described in the medical literature.

\section{References}

1. Ellenson LH, Carinelli SG, Cho KR, Kim KR, Kupryjanczyk J, et al. (2014) Endometrioid tumors. In: Kurman RJ, Carcangiu ML, Herrington CS, Young RH, WHO Classification of Tumors of Female Reproductive Organs. ( $4^{\text {th }}$ edn), International Agency for Research on Cancer, Lyon, France, 29-30.

2. Seidman JD, Cho KR, Ronnett BM, Kurman RJ (2011) Surface epithelial tumors of the ovary. In: Kurman RJ, Ellenson LH, Ronnet BM, Blaustein's Pathology of the Female Genital Tract. (6 $6^{\text {th }}$ edn), Springer, 749.

3. Longacre TA, Gilks CB (2009) Surface epithelial stromal tumors of the ovary. In: Nucci MR, Oliva E, Gynecologic pathology. ( $1^{\text {st }}$ edn), Churchill Livingston, 426-432.

4. Murray MP, Park KJ (2011) Pathology of Endometrioidtumors. In: Soslow RA, Tornos C, Diagnostic pathology of ovarian tumors. (1 ${ }^{\text {st }}$ edn), Springer, 75-76. 